\title{
TERREIRO DO EGITO: memórias e resistência em São Luís do Maranhão
}

\author{
Carolina C. de Souza Martins* \\ Elio de Jesus Pantoja Alves**
}

\begin{abstract}
RESUMO: O trabalho descreve e analisa a experiência da busca pela ancestralidade de um grupo de pais e mães de santo, tendo como referência o Terreiro do Egito, considerado território sagrado por antigos moradores e por praticantes do Tambor de Mina, religião de matriz africana presente no Maranhão. O terreiro está localizado na comunidade rural de Cajueiro, às margens da baia de São Marcos, município de São Luís do Maranhão, na porção sudoeste da Ilha do Maranhão ${ }^{1}$ que desde os anos de 1980 tem sido ameaçada pela expansão do Complexo Portuário de São Luís ${ }^{2}$ e por atividades industriais. Nesse sentido, procura mostrar mais recentemente, como a memória coletiva é acionada diante da ameaça de perda deste território.
\end{abstract}

PALAVRAS-CHAVE: Comunidades rurais; Memórias; Território sagrado.

\section{Terreiro do Egito: memories and resistance in São Luís do Maranhão}

ABSTRACT: This job describes and analyses the experience of searching for the ancestry of a group of mães de santo and pais de santo, whose reference is Terreiro do Egito, which is considered a holy territory by old residents and by the ones who follow Tamor de Mina -- an African religion common in Maranhão. Terreiro de Mina is localized in Cajueiro's rural community, near São Marcos' bay, in the county of São Luís, southwest of Maranhão island[i], place that is being threatening since the beginning of the 1980s because São Luís Portuary Complex[ii] has been expanding for industrial activities. That's why this article intends to show recently how the collective memory is triggered when the threat of losing this territory is a reality.

KEYWORDS: Rural communities; Memories, Holy territory

\section{Terreiro do Egito: recuerdos y resistencia en São Luís do Maranhão}

RESUMEN: El trabajo describe y analiza la experiencia de la búsqueda de la ancestralidad de un grupo de padres y madres de santo, teniendo como referencia el Terreiro de Egito, considerado territorio sagrado por antiguos habitantes y por practicantes del Tambor de Mina, religión de matriz africana presente en Maranhão . El terreiro está ubicado en la comunidad rural de Cajueiro, a orillas de la bahía de San Marcos, municipio de São Luís do Maranhão, en la porción suroeste de la Isla de Maranhão que desde los años 1980 ha sido amenazada por la expansión del Complejo Portuario de São Luís y, por actividades industriales. En ese sentido, procura mostrar más recientemente, como la memoria colectiva es accionada ante la amenaza de pérdida de este territorio.

PALABRAS CLAVE: Comunidades rurales, Memorias, Territorio sagrado.

* Doutoranda em História Social pelo Programa de Pós-Graduação em História da Universidade Federal Fluminense (PPGH/UFF); Membro do Grupo de Pesquisa Religião e Cultura Popular (GPMINA/UFMA) e do Grupo de Pesquisa Cultura Negra no Atlântico (CULTNA/UFF). Email: caroldesouzamartins@gmail.com

** Doutor em Sociologia pela Universidade Federal do Rio de Janeiro. Atualmente, Professor do Departamento de Sociologia e Antropologia na Universidade Federal do Maranhão. Contato: Universidade Federal do Maranhão, Centro de Ciências Humanas, Departamento de Sociologia - Av. dos Portugueses, 1966, Bacanga, CEP 65080-805, São Luís - MA, Brasil. E-mail: elio@ufma.br. 


\section{Introdução}

Neste artigo destacaremos uma experiência de compartilhamento da memória coletiva de lideranças comunitárias e de pais e mães-de-santo a partir de um referencial ancestral comum que é o Terreiro do Egito, um lugar considerado sagrado por praticantes das religiões de matriz africana, localizado na comunidade do Cajueiro na zona rural do município de São Luís do Maranhão ${ }^{3}$. A discussão sobre as religiões de matriz africana foi se impondo como uma realidade nesta comunidade em decorrência da possível instalação de um porto privado e a iminente ameaça aos espaços sagrados e aos terrenos dos moradores quando realizávamos atividades de pesquisa de campo em julho de 2015. Para compor o artigo, recorremos a uma bibliografia básica sobre a temática e realizamos seis entrevistas com antigos moradores direcionadas para a memória do Terreiro do Egito. Além das entrevistas, realizamos conversas informais e participamos de reuniões com lideranças da comunidade e lideranças religiosas de terreiros de São Luís.

No Terreiro do Egito se praticava o Tambor de Mina ou a Mina, desde os meados do século XIX até os anos de 1970 quando foi desativado. Segundo Sérgio Ferretti (2006, p. $1)^{4}$,Tambor de Mina é uma religião na qual se realizam cultos aos voduns:

[...] O culto dos voduns foi trazido para o Brasil e para as Américas com escravos procedentes do antigo Reino do Daomé. Por essa razão, além do Daomé, o Haiti e o Maranhão, tornaram-se "terras" dos voduns de onde a religião se expandiu para outras regiões. O antigo Reino do Daomé na África Ocidental, conhecido de aproximadamente 1600 a 1900, sediado na região pertencente ao Benin, falante da língua Ewe-Fon, conhecida no Brasil como jeje, foi o berço desta religião.

[...] Os negros procedentes desta região foram conhecidos no Brasil como negros mina e a religião dos voduns por eles praticada é conhecida até hoje, sobretudo no Maranhão e na Amazônia, como Tambor de Mina.

Recorrendo aos trabalhos de Sérgio Ferretti (2006), Mundicarmo Ferretti (2004; 2015) e de Moreira Lima Neto (2007) notamos a relevância das religiões de matriz africana na formação cultural e religiosa do Maranhão, bem como com relação a desdobramentos importantes referentes à história do estado.

O engenheiro civil maranhense Bento Moreira Lima Neto, que nos anos de 1970 trabalhou na construção do Porto de Itaqui, em seu livro Histórias do Porto do Itaqui (2007), descreve uma série de casos de desaparecimento de mergulhadores em 1971, atribuídos à ação dos encantados ${ }^{5}$, no caso a Princesa Iná que havia sido contrariada com a construção do porto:

Antes de começar seu trabalho de manhã cedo, vestia uma roupa negra de mergulhador e se dirigia para a beira do cais com uma pequena sacola. Em 
determinado ponto, em frente ao armazém, parava para se sentar no chão, baixava a cabeça e fazia uma oração, sempre sozinho, em seguida, abria a sacola de onde retrava alguns colares coloridos confeccionados com dentes de peixes e animais, ossos ou qualquer coisa assim, que ele repassando na ponta dos dedos, devagar, e, sem parar de rezar, colocando em volta o pescoço em um ritual místico e intimo [...] (p. 182)

[...] Aparentado a calma de sempre, colocou a máscara que se ligava ao tubo de oxigênio em terra, por uma mangueira fina e negra, e fixou a corda d segurança na cintura, que também serva para se comunicar com o ajudante de terra e onde ficavam amarrados os pesos de chumbos que permitia afundar mas rápido. Caminhou para o mar, serenamente, como fazia todos os dias e logo desapareceu em suas águas escuras e sem ondas [...] (p. 182)

Conforme Moreira Neto, o líder religioso Jorge de Itacy, ou como era mais conhecido, Jorge da Fé em Deus e Sebastião do Coroado, pais de santo bastante respeitados em São Luís foram convidados pelas autoridades para pedir permissão, através de obrigações, para a Princesa Ina, ou Iná, filha do Rei Sebastião, encantada no fundo da baía de São Marcos, para que ela pudesse conceder autorização à continuidade das obras do porto. Esta encantada, segundo descreve este autor, ficou revoltada pela perturbação em seu palácio com as obras da construção do Porto do Itaqui, ocorrendo com isto vários acidentes e mortes.

Um mistério realmente difícil de explicar a não ser pelos babalorixás que não perderam a oportunidade de acusar a Princesa Iná pelo desaparecimento do jovem mergulhador, místico e dedicado ao trabalho [...] (p. 183).

O Porto de Itaqui, a partir dessa ótica, é considerado uma morada de encantados, uma encantaria, um lugar sagrado. Segundo Mundicarmo Ferretti (2004), as moradas dos encantados são considerados lugares sagrados e que transcendem as delimitações dos espaços físicos onde se localizam os lugares de festas, de cultos. ${ }^{6}$ As encantarias, como se costuma denominar estes lugares, são considerados aqui de modo geral, como um complexo fenômeno religioso, envolvendo tradições, sincretismos, cultos, rituais, crenças, simbologias, normas, cosmovisão e memórias coletivas compartilhadas entre seus praticantes. A seguir, apresentamos mais detalhadamente a questão do conflito na comunidade do Cajueiro e como o Terreiro do Egito e as encantarias se inserem neste contexto.

\section{A comunidade do Cajueiro: espaço sagrado, território em conflito}

A comunidade do Cajueiro é uma das inúmeras comunidades rurais localizadas na porção sudoeste da Ilha do Maranhão. Como dito antes, antigos moradores testemunharam a construção do Porto de Itaqui e mantém viva a memória do que ocorrera durante as obras; os 
impactos de toda ordem e, sobretudo, as alterações no modo de vida em função da dragagem e consequente destruição de ecossistemas pesqueiros, áreas de manguezais, fundamentais para as comunidades da região. Desde o início da construção do porto as comunidades passaram a sofrer ameaças de deslocamentos compulsórios ${ }^{7}$ para instalação de empreendimentos portuários e industriais na porção sudoeste da Ilha do Maranhão. Os territórios de um modo geral, assim como os territórios sagrados, desde então, passaram a ser pressionados pela expansão industrial potencializada com a instalação do Complexo Portuário de São Luís.

Nos anos de 1990 com o avanço das atividades industriais e portuárias, inúmeras empresas ligadas principalmente ao setor mínero-metalúrgico e indústrias diversas também foram atraídas para a região, aumentando a especulação imobiliária e acirrando os conflitos em função da compra e venda ilegal de lotes de terras em áreas tradicionalmente ocupadas por comunidades de pescadores-lavradores, nas quais existem também inúmeros lugares sagrados.

Alves (2014) destaca que por volta dos anos de 1990 as comunidades passaram a perceber que os recursos naturais estavam se esgotando. Mesmo algumas famílias que trabalhavam com extração mineral, assim como aquelas que extraíam madeiras do mangue para produção de carvão tiveram que suspender estas atividades em função dos prejuízos ao ambiente, além do prejuízo que já sofriam pelo impacto das grandes indústrias. É a partir desta "percepção" que lideranças locais, entre estas aquelas já engajadas em movimentos de pescadores passaram então a mobilizar as comunidades em torno de um projeto político unificado de uma Unidade de Conservação na modalidade Reserva Extrativista ${ }^{8}$.

A reivindicação legal da área se constituiu num dispositivo deação coletiva importante pelo fato de que permitiria a permanência das comunidades na área explorando seus recursos, ainda que obedecendo a um estatuto e um plano de manejo, caso a RESEX venha ser decretada. Denominada de Reserva Extrativista de Tauá-Mirim, o projeto tem mobilizado segmentos sociais importantes e redes de movimentos que passaram a aderir a essa causa. Embora não tenha sido legalmente decretada, a RESEX foi criada autonomamente por meio de uma assembleia popular em 17 de maio de 2015, quando foi eleito o Conselho Gestor da RESEX representado por diversos movimentos sociais e principalmente por moradores das comunidades incluídas no projeto. Abaixo (Figura 1), observa-se a RESEX e a localização da comunidade do Cajueiro em círculo. 
Figura 1: Reserva Extrativista de Tauá-Mirim

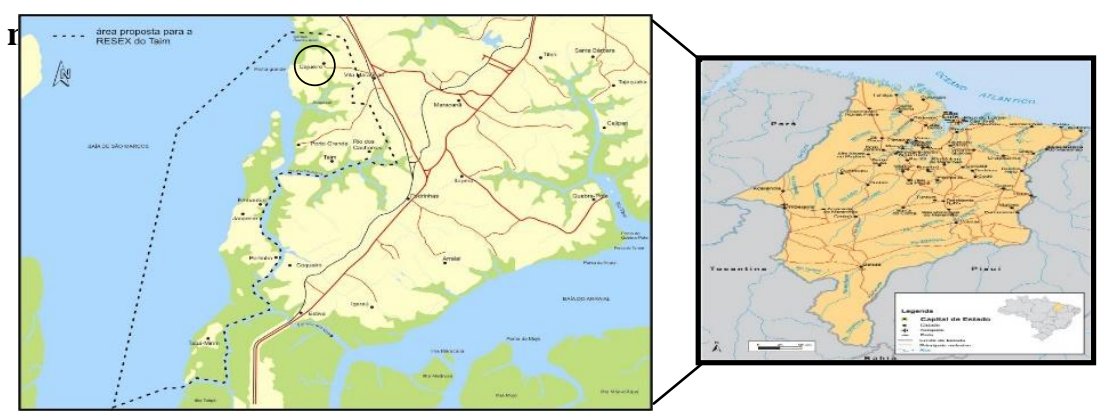

Fonte: Adaptação Laudo Socioeconômico e Biológico da Reserva Extrativista do Taim (IBAMA, 2007)

Em 2002, a reivindicação da Reserva Extrativista de Tauá-Mirim foi retomada com a iminência de instalação de um polo siderúrgico em São Luís, justamente projetado para ser instalado na área reivindicada para a RESEX. O polo siderúrgico foi inviabilizado em grande medida pela pressão realizada pelos movimentos de reação à instalação, protagonizados pelas lideranças comunitárias ${ }^{9}$.Entretanto, em 2009, houve o deslocamento da comunidade Vila Madureira, para instalação da usina termelétrica Porto de Itaquí, onde existia um terreiro de tambor de mina e, mais recentemente, a ameaça ao Terreiro do Egito continua para a instalação de um porto privado. Nas reuniões mensais do Conselho Gestor da RESEX, a questão dos territórios sagrados tem sido discutida diante da iminente possibilidade de deslocamento destas comunidades. No projeto da RESEX, lideranças comunitárias têm sensibilizado os terreiros de mina descendentes do Terreiro do Egito no sentido de encaminhar ações concretas exigindo dos órgãos competentes como, por exemplo, o IPHAN e a Secretaria de Estado de Meio-Ambiente e Recursos Naturais, respectivamente para garantir a proteção jurídica deste lugar sagrado enquanto lugar de memória e exigir o cancelamento do licenciamento para instalação deste empreendimento portuário que, na visão das lideranças das comunidades, trará grandes prejuízos ao modo de vida e à memória dos povos de terreiro.

O Cajueiro é uma comunidade rural que têm mais de cem anos, considerando que entrevistamos moradores com 90 anos que lembram quando criança das festas do Terreiro do Egito. Lembram dos pais e de parentes que frequentaram este terreiro, entre os quais havia os praticantes de tambor de mina. Lembram que desde essa época no Cajueiro havia famílias de pescadores-lavradores e extrativistas. Sendo localizada às margens da baía de São Marcos e a mais próxima ao Complexo Portuário, esta comunidade tem sido objeto de investidas de desapropriação para instalação de estruturas logísticas e portuárias. A comunidade é 
politicamente representada pela União de Moradores Proteção de Jesus do Cajueiro e se constitui de cinco núcleos de povoamento, sendo eles: Parnauaçú, Andirobal, Guarimanduba, Cajueiro e Morro do Egito, sendo este último núcleo, um dos mais antigos e que remete à memória dos moradores aos antepassados vindos da África escravizados e que buscaram um refúgio naquela região da Ilha. ${ }^{10}$

No ano de 1998, após muitos conflitos de terras e reivindicações das comunidades, o Governo do Maranhão, por meio do Instituto de Terras do Maranhão (ITERMA), declarou com Decreto Governamental a área do Cajueiro como assentamento rural por meio de "Escritura Pública de Condomínio" com um total de seiscentos e dez hectares hum ares e setenta e dois centiares, dentro da Gleba "A" Tibiri-Pedrinhas, margeando a baía de São Marcos ${ }^{11}$.

Após anos de lutas de resistências, em 2014, a comunidade de Cajueiro passou a ser ameaçada em função do projeto deconstrução de um porto da empresa WPR - São Luís Gestão de Portos e Terminais Ltda, do grupo WTorre. O Terminal de Uso Privado (TUP) da WPR foi anunciado e autorizado pelo Ministério dos Transportes em janeiro de 2016, com apoio do Governo do Maranhão e da Prefeitura de São Luís, com previsão de investimentos governamentais de $\mathrm{R} \$ 1,782$ bilhão $^{12}$.

Em 2014, houve uma intensa mobilização na comunidade do Cajueiro quando seus moradores passaram a sofrer ameaças por meio de propostas de indenizações cujos valores seriam incompatíveis com os bens; ameaças por meio de coerção direta quando foram impedidos por seguranças privados, contratados pela empresa, de circularem livremente na área, sendo controlados na hora de sair e de chegar a suas casas e de construir benfeitorias em seus terrenos. Diante de tal situação, os moradores diretamente afetados na área do Parnauaçú, onde seria instalado o porto, passaram a realizar uma série de reuniões entre junho a outubro de 2014(ALVES, 2016).

Como dito antes, o território do Cajueiro é composto de pequenos núcleos de povoamento que se distinguem internamente. $\mathrm{O}$ empreendimento portuário foi planejado para ser instalado na praia do Parnauaçú, uma das praias que dá acesso à baía de São Marcos. Conforme relato dos moradores do Cajueiro, a construção deste empreendimento impediria o acesso dos pescadores à baía, dificultando assim suas atividades pesqueiras, como já ocorrera com outras comunidades que foram deslocadas para a instalação no Porto de Itaqui, por exemplo, a Praia do Boqueirão. Por outro lado, na concepção funcional logístico-portuária por parte de agências estatais e de investidores, a área é concebida como um lugar de "vocações" 
portuárias e industriais, considerando sua aproximação geográfica à estrutura logística mina de ferro (Serra de Carajás -PA) - ferrovia (Ferrovia Carajás-Itaqui) - porto (Complexo Portuário de São Luís). Dentro deste cenário de disputa entre diferentes concepções de uso dos territórios foi retomada a situação do Terreiro do Egito.

O Morro do Egito, como os moradores comumente se referem ao local onde se encontra o antigo Terreiro do Egito, é uma elevação de terra às margens da baía de São Marcosprotegida por pequenas e grandes árvores de cajueiros. Do local se tem uma visão panorâmica da baía e de onde se vê também parte do Complexo Portuário de São Luís e os navios. Segundo os relatos, o terreiro deixou de funcionar regularmente desde os anos de 1970, mas esporadicamente seus descendentes continuam a frequentar o local para prestarem homenagem aos guias espirituais e realizar obrigações e oferendas.

Conforme entrevista de Pai Euclides da Casa Fanti-Ashanti ${ }^{13}$, a origem deste terreiro remonta ao século XIX, por volta de 1860 e 1870. Também denominado de Ilê Nyame, foi fundado por Basília Sofia, uma negra, cujo nome privado era Massinocô Alapong, que veio de Cumassi, Costa do Ouro, hoje, Gana. Basília Sofia teria chegado ao Maranhão em 1864 e faleceu em 1911. A partir de 1912, o Terreiro ficou sob a responsabilidade de Mãe Pia, que o chefiou por cinquenta e cinco anos, iniciando outros médiuns que posteriormente fundaram seus próprios terreiros em São Luís e em outras cidades do Brasil.

Até os anos de 1970, quando o terreiro ainda funcionava e ocorriam as festas, o acesso era muito difícil, não havia estradas. Antigos moradores do Cajueiro em entrevista relatam que era muito mais fácil chegar por via marítima ao local, inclusive partindo de outros bairros de São Luís. Muitas pessoas procuravam o Terreiro do Egito durante os rituais em busca de tratamento, pois, era conhecidocomo um terreiro de cura. Alguns médiuns iniciados no Terreiro do Egito foram chamados para pedir permissão à Princesa Ina para a construção do Porto através de obrigações. Levantam-se questões se essas obrigações demandadas aos pais de santo por autoridades estatais para pedir licença aos encantados para a construção do porto não teriam contribuído para o encerramento das atividades do Terreiro do Egito, mas esta é uma hipótese que precisa ser indagada.

\section{Recorrer à memória coletiva de um lugar sagrado}

Em 2015, diante da iminente possibilidade de deslocamento da comunidade do Cajueiro para a construção de um novo porto, as lideranças locais acionaram a União de Moradores, os membros do GEDMMA (Grupo de Estudos: Desenvolvimento, Modernidade e 
Meio Ambiente/UFMA) e aos membros do GPMINA (Grupo de Pesquisa "Religião e Cultura Popular/UFMA), solicitando reuniões para discutir com a comunidade do Cajueiro e com os pais e mães de santo descendentes do Terreiro do Egito, a situação de ameaça de todo o território e a necessidade de preservá-lo. No diálogo com os pesquisadores foi explicitada a antiga luta do Cajueiro, assim como de todas as comunidades daquela área pela regularização fundiária desde os anos de 1980 e a situação de ameaças e dos casos de "grilagem"14 de terras registrados pela Comissão Pastoral da Terra (CPT) em 2014.

Após as reuniões, sob a orientação e companhia de uma liderança do Cajueiro, membros do GEDMMA e do GPMINA realizaram uma série de entrevistas com antigos moradores entre julho e agosto de 2015, sendo estas as fontes para a organização das informações aqui apresentadas. Foi realizado um levantamento de informações e contatos com descendentes do Terreiro do Egito; foi elaborado uma genealogia de diferentes gerações de pais e mães de santo, tendo como referência os iniciados no Terreiro do Egito sob a orientação da antropóloga Mundicarmo Ferretti, que naquele momento havia elaborado um artigo a ser publicado (M. FERRETTI, 2015) e que serviu de base para a localização dos principais terreiros, cujos representantes foram contatados. Com estes foi feita uma articulação partindo da memória do Terreiro do Egito e a sensibilização sobre a relevância de sua preservação. Entre os dias 15 e 20 de novembro de 2015 foram realizadas 2 reuniões entre lideranças da comunidade de Cajueiro, pais e mães de santo, frequentadores de terreiros e estudiosos do tema e membros de grupo de estudos que resultaram na elaboração de um manifesto através de uma Carta Aberta, encaminhada e protocolada nos órgãos governamentais.

Posteriormente, em 22 novembro de 2015, foi organizado um ato simbólico com leitura da Carta Aberta $^{15}$, exigindo a preservação do Terreiro do Egito enquanto território sagrado e do Cajueiro como comunidade tradicional e uma caminhada com a presença de moradores da área, pais, mães e filhos de santo, pesquisadores e membros de movimentos sociais. A caminhada da União de Moradores até o Terreiro do Egito culminou com o levantamento do mastro com bandeira branca, o "pau da paciência", demarcando o território sagrado. Abaixo, um trecho da Carta Aberta "Pelo Terreiro do Egito e Território do Cajueiro":

Nós, comunidades tradicionais de matriz africana, descendentes do Terreiro do Egito e as comunidades que compõem o território do Cajueiro - Guarimanduba, Parnauaçú, Andirobal e Cajueiro - vimos através desta Carta, manifestar nossa unidade em torno da defesa de nossa história, de nossas religiões, de nossos antepassados e de nossa herança cultural. O território das comunidades tradicionais do Cajueiro está localizado na Zona Rural II de São Luís-MA, na porção sudoeste da 
Ilha, às margens da baía de São Marcos, sendo o acesso principal pela BR-135 nas proximidades da Vila Maranhão. O Terreiro do Egito, lugar de cultos afrobrasileiros cujas narrativas remontam ao Século XIX, é um dos mais antigos do Brasil e está situado no território do Cajueiro [...]

[...] Em toda diáspora afro - americana, o Maranhão se configura pela singularidade de ter sido o único local no qual o Tambor de Mina se constituiu como religião matriz dos cultos africanos, fundada em meados do século XIX na capital. O Terreiro do Egito, juntamente com a Casa das Minas, a Casa de Nagô, o Terreiro da Turquia e o Terreiro do Justino (fundado em 1896) são as matrizes das comunidades afroreligiosas no estado. O terreiro do Egito é um lugar sagrado e merece ser respeitado; é um símbolo de resistência, pois enfrentou os limites impostos por uma sociedade marcada pela escravidão; enfrentou todos os tipos de intolerância religiosa e cultural. Resistiu e resistirá! Seus herdeiros hoje lutam pelo seu reconhecimento, pela sua importância para o povo do Maranhão e para a história do Brasil.

A defesa pela preservação e reconhecimento como lugar sagrado do Terreiro do Egito, entretanto, não é uma luta isolada! Associa-se com a luta pela defesa do território do Cajueiro onde está situado. Batalha que vem sendo travada há décadas, por homens e mulheres de coragem, verdadeiros guardiões desse território, mas que vêm sofrendo ameaças e violências e intimidações de todo modo por aqueles que querem dele se apropriar, torná-lo mercadoria: ameaça por deslocamento para instalação de indústrias e empreendimentos portuários, ameaças pela poluição ambiental, ameaça pela destruição dos bosques de mangue que protegem o território sagrado. Os peixes, a água, os rios, os igarapés, o solo e o ar que se respira, são fundamentalmente, elementos conectados com a vida comunitária nesse território étnico. O Cajueiro é formado por pessoas que nasceram, cresceram e querem permanecer ali, são povos tradicionais! Remanescentes de quilombos! Exigimos políticas sociais voltadas à pesca e a agricultura, exigimos escolas, serviços de saúde, melhorias e pavimentação da estrada, melhorias nos transportes, fiscalização às empresas poluidoras por parte dos governos; exigimos a preservação da natureza e o respeito ao nosso modo de viver, ao nosso modo de ser e de sonhar, de praticar nossas religiosidades livremente!"

\section{"Batalhas de memórias" e desdobramentos}

Desde o final de 2014 até hoje a ameaça ao Cajueiro tem se intensificado. Após o evento de 22 de novembro de 2015, houve uma relativa visibilidade do Terreiro do Egito com divulgação através de matérias jornalísticas e o apoio da Defensoria Pública Estadual que tem questionado a legalidade na compra dos terrenos e no processo de licenciamento ambiental. A área reivindicada para a construção do porto é de 200 ha na qual se encontram inúmeras nascentes, brejos, palmeiras de juçaras e de coco-babaçu, além de inúmeras árvores frutíferas e lugares sagrados. Desta área já foram destruídos mais de 60 ha e os funcionários da empresa já entraram com máquinas em terrenos cujos donos não negociaram. A área do Terreiro do Egito em sua delimitação física está de fora da área do projeto do porto, mas será diretamente afetado, pelo fato de que o espaço sagrado é bem mais amplo, tendo interferência de maquinário na parte terrestre e na parte aquática, além do fluxo de embarcações de grande porte e de navios. A comunidade, através de suas lideranças em conjunto com outros 
movimentos tentam barrar a obra na justiça, mas há grandes interesses em jogo. No final de dezembro de 2017, após inúmeras manifestações e denúncias conseguiram suspender temporariamente as obras.

Em reuniões com pais e mães de santo no Cajueiro ainda em 2015, foi feita a sugestão da construção de um "barracão" no local com a perspectiva de desenvolver atividades culturais relacionadas às tradições afro-brasileiras como forma de ocupar e dar visibilidade ao Terreiro. Foi pensada também uma programação envolvendo as escolas de São Luís para que a memória pudesse ser valorizada. Estas ações, entretanto, não se concretizaram em grande medida pela situação de conflito que foi gerada com a notícia de instalação do porto.

Há conflitos que tem interferido no processo. Alguns dos antigos moradores entrevistados frequentaram o Terreiro do Egito, mas hoje são membros das igrejas evangélicas que recorrentemente manifestam suas posições orientadas pelo distanciamento à adesão à causa do Terreiro do Egito o que interfere na interlocução com os pais e mães de santos que reivindicam a garantia do território sagrado. Embora ultimamente tenha apresentado maior abertura política para discutir a situação, grande parte da comunidade evangélica, mantém um estranhamento às questões religiosas de matriz africana. Se por um lado a inserção do Terreiro do Egito na pauta reivindicatória pode potencializar a luta política e a visibilidade do Cajueiro, por outro, o conflito religioso interno tem interferido na coesão interna. Notamos hostilidades com relação às religiões afro-brasileiras, embora, entre os mais antigos, seja menos perceptível. Nas entrevistas relatam que viam o navio encantado e participavam das festas. Sérgio Ferretti (2016, p. 9) relata em seu artigo que:

A liderança da comunidade fez questão de frisar que os evangélicos e os afrobrasileiros estavam juntos na luta pela terra, mas no momento da reza, cada um tinha o seu modo e não deviam se misturar. Assim, embora os preconceitos continuem, o objetivo comum parece que supera as hostilidades existentes, o que parece um dado muito positivo.

Trata-se de uma "batalha de memórias", termo usado aqui no sentido em que é dado por M. Pollak em "Memória, esquecimento e silêncio" (1989), ao falar de memória estruturada com suas hierarquias e classificações, uma memória que define o que é comum ao grupo e o difere de outro, reforçando os sentimentos de pertencimento. A memória comum terá essa função de reforçar a coesão social, não pela coerção, mas pela adesão afetiva ao grupo através de um processo de negociação que concilia memória coletiva.

No caso da busca pela memória ancestral do Terreiro do Egito, a conexão tem ocorrido, sobretudo, pelo afeto e mútua reciprocidade entre os descendentes em diferentes 
gerações. Embora estes descendentes não tenham residência no Cajueiro, há uma conexão religiosa e afetiva com aquele território, por assim dizer, um sentimento de pertencer a um ancestral comum. Sentimento que ajudou na reconfiguração de uma rede articulada de terreiros de Mina que foi construída através de uma genealogia organizada por pesquisadores e membros dos terreiros.

Seguindo ainda a análise do autor supracitado, vale a pena notar a importância de "memórias subterrâneas" que, como parte integrante das culturas minoritárias e dominadas, se opõem à memória oficial, no caso a memória nacional que tem um caráter uniformizador. É nesse sentido que usamos a noção de "batalhas de memória", e que ganha significado aqui, sobretudo, considerando o Brasil atual onde as religiões de matriz africana têm sido rotineiramente alvo de ataques de intolerância religiosa. Mas a partir do momento em que essas memórias emergem e conseguem ocupar o espaço público, reivindicações múltiplas e dificilmente previsíveis se acoplam a essa disputa de memória. Daí a importância dos momentos propícios para que as memórias subterrâneas sejam expressas.

São as narrativas que mantém essa memória viva, o silêncio não conduz ao esquecimento. Essas lembranças são transmitidas no meio familiar, em associações, em redes de sociabilidade afetiva e/ou política. A memória, essa operação coletiva dos acontecimentos e das interpretações do passado que se quer salvaguardar, se integra, como vimos, em tentativas mais ou menos conscientes de definir e de reforçar sentimentos de pertencimento e de fronteiras sociais entre coletividades de tamanhos diferentes. A memória coletiva tem ainda a função de definir seu lugar respectivo, seu território. Isso significa fornecer um quadro de referências, um trabalho de "enquadramento de memória". O trabalho de enquadramento não deve ser arbitrário, mas deve responder a exigências de justificação. Ele reinterpreta o passado. Esse trabalho de enquadramento tem seus atores profissionalizados, os porta-vozes. Escolha de testemunhas autorizadas para uma produção de discursos organizada.

No caso da Praia do Boqueirão, onde se localiza o Parnauaçú e o Terreiro do Egito situados no território do Cajueiro, é um ambiente que para os pais e mães-de- santo descendentes deste terreiro, as suas fronteiras transcendem sua base geográfica e material. Trata-se de um "lugar sagrado", "lugar de memória" de seus ancestrais que remonta ao século XIX, período da escravidão quando os negros escravizados formaram ali um quilombo ${ }^{16}$.

Os antigos moradores do Cajueiro narram que conheceram pessoas que frequentaram as festas no Terreiro do Egito, e estes, assim como no relato de pais e de mães-de-santo, incluindo a mais antiga moradora do Cajueiro, avistavam na baía a chegada do navio 
iluminado de Dom João com a tripulação de entidades encantadas que ali permaneciam quando se realizavam os trabalhos entre os meses de dezembro e janeiro durante as festas de Santa Luzia, São Sebastião e São Benedito. E no final das festas, ao retomar ao mar, o navio era ali afundado lentamente ${ }^{17}$.

Oengenheiro civil Bento Moreira Lima Neto, cujos relatos foram mencionados inicialmente, diz ainda em seu livro, ora em tom de seriedade, ora considerando como folclore e/ou lenda o que ouviu de funcionários sobre a aparição de navios que quando se preparavam para iniciar as manobras de atracação, desapareciam misteriosamente. Ele relata que após estas visões, estes funcionários pediam demissão e partiam para nunca mais voltar a trabalhar no porto. De uma forma ou de outra, a apropriação do tema pelo engenheiro demonstra a resistência dessa memória coletiva e de certa forma, o lugar que ganhou num momento histórico e econômico importantes em que a força política do discurso racionalizador do desenvolvimento e do progresso se tornou também por outro lado, uma espécie de crença que não aceitava explicações de outra ordem e, sobretudo, pelo fato de interferir nos rumos das ações dos agentes políticos e econômicos locais. Diz o engenheiro em seu livro, referindo-se à Princesa Iná:

\begin{abstract}
Não sei não, mas se tivesse prestígio na CVRD, mandaria bater, na discreta praia do Boqueirão, os mais afamados tambores-de-mina e convidaria o povo da cidade para uma grande festa, assim como fez Haroldo Tavares quando foi Prefeito da capital, em homenagem à cortesã presunçosa, rogando por sua proteção, e convocaria a presença de todos os babalaôs da região e suas acompanhantes para entoarem hinos de louvor e dançarem em ruidosa cerimônia sob o céu enluarado.(LIMA NETO: p.604).
\end{abstract}

\title{
Considerações Finais
}

O caso do Cajueiro e Terreiro do Egitotem ganhado visibilidade com relativa presença dos órgãos ligados ao poder judiciário, tais como a Defensoria Pública do Estado do Maranhão e Ministério Público Estadual e Ministério Público Federal e mais recentemente, a intervenção em certa medida do Instituto de Patrimônio Histórico, Artístico Nacional (IPHAN) requisitado para discutir a situação de sítios históricos e arqueológicos encontrados na área. Diante do dilema da construção ou não da questionável obra do porto, a comunidade do Cajueiro ganhou visibilidade na mídia. No momento em que estamos concluindo a escrita deste artigo, entre novembro e dezembro de 2017, a TV Mirante, em seu Jornal local de meio dia, apresentou uma reportagem sobre mais uma violência sofrida pela comunidade. Desta vez, a obstrução do fornecimento de água na comunidade em decorrência da destruição da instalação dos canos e poços de distribuição de água, ação atribuída à empresa que pretende 
construir o porto. Na matéria o Jornal destaca a importância do terreiro do Egito como um lugar de memória de um dos terreiros de Mina mais antigos do Maranhão e que deve ser preservado. Em fins de dezembro de 2017, a comunidade do Cajueiro continua a ser alvo de violência com a operação de terraplanagem com máquinas, destruindo brejos, nascentes e babaçuais, ambientes fundamentais para os meios de vida da comunidade. Conforme relatam as lideranças, dos 200 ha supostamente adquiridos pela empresa, 60 ha já foram destruídos. Os moradores antigos denunciam também a entrada de máquinas em seus terrenos sem permissão ou negociação entre as partes.

O coletivo constituído a partir da retomada do terreiro do Egito em 2015, entretanto, tem procurado inserir a questão da zona rural como parte de todo processo de discussão da cidade de São Luís, incluindo os membros de religiões de matriz africana, sobretudo membros de terreiro de mina descendentes do Terreiro do Egito. A área do Terreiro do Egito, no entanto, ficou de fora da área do projeto do porto, mas a comunidade do Cajueiro continua sendo alvo de violação de seus direitos básicos. Atualmente se tenta articular novas estratégias de unificação politica entre os terreiros com a intenção de dar visibilidade à importância da permanência do Cajueiro em seu território sem dissociar a sua conexão com esta memória. Esta intenção, entretanto, se coloca como um desafio tendo em vista as investidas empresariais-estatais frente aos processos de resistência.

\section{Notas}

\footnotetext{
${ }^{1}$ Ilha do Maranhão é o nome oficial da ilha onde se situa o município de São Luís. É também chamada de Upaon-Açú (Ilha Grande), nome que seria designado pelos povos indígenas antes do período colonial. A Ilha do Maranhão é constituída por um arquipélago com mais de cinquenta ilhas com variadas origens e dimensões. A maior delas é a Ilha de São Luís, onde se localiza a capital do Maranhão. Na Ilha do Maranhão estão localizados os municípios de São Luís, Raposa, Paço do Lumiar e São José de Ribamar (MARANHÃO, 2004, apud ALVES, 2014).

${ }^{2}$ O Complexo Portuário de São Luís está localizado na baía de São Marcos, a 11 km do centro de São Luís, capital do Maranhão. É formado por três portos: Porto de Itaqui (administrado pela estatal estadual Empresa Maranhense de Administração Portuária - EMAP), Ponta da Madeira (pertencente à Cia. Vale) e Porto da Alumar (pertencente ao Consórcio de Alumínio do Maranhão, formado pelas empresas Alcoa, BHP Billiton e Rio Tinto Alcan) (ALVES, 2014).

${ }^{3}$ Este artigo é resultado de atividades de pesquisa de campo iniciadas em julho de 2015, envolvendo membros do GPMINA (Grupo de Pesquisa "Religião e Cultura Popular/UFMA) e do GEDMMA (Grupo de Estudos: Desenvolvimento, Modernidade e Meio Ambiente/UFMA. Estas atividades estão inseridas no Projeto de Pesquisa "Repertórios e argumentos da mobilização política na Zona Rural II de São Luís - MA: territórios, ambientes e recursos naturais em questão" coordenado pelo Prof. Dr. Elio de Jesus Pantoja Alves (DESOCIUFMA) que conta com o apoio financeiro da Fundação de Amparo à Pesquisa e ao Desenvolvimento Científico e Tecnológico do Maranhão (FAPEMA). Agradecemos o apoio da FAPEMA.

${ }^{4}$ Publicado em: http://repositorio.ufma.br:8080/jspui/bitstream/1/300/1/A\%2520TERRA\%2520DOS\%2520VODUNS.pdf

${ }^{5}$ Os 'encantados' são as entidades espirituais recebidas em transe mediúnico em terreiros de São Luís. Sobre os encantados e a Encantaria maranhense, ver FERRETTI, Mundicarmo. A Encantaria de Barba Soeira: Codó,
} 
capital da magia negra? São Paulo: Siciliano, 2001 e FERRETTI, Mundicarmo M. R.. Maranhão Encantado: encantaria maranhense e outras histórias. São Luís: UEMA. 2000.

${ }^{6}$ FERRETTI, M. Lugares Sagrados e Encantarias Maranhenses. Anais da 56 ${ }^{a}$ Reunião Anual da SBPC Cuiabá, MT - Julho/2004.

${ }^{7}$ Conforme Magalhães (2007, p. 14), "deslocamento compulsório" designa "o processo pelo qual determinados grupos sociais, em circunstâncias sobre as quais não dispõem de poder de deliberação, são obrigados a deixar ou a transferir-se de suas casas e/ou de suas terras. Há, portanto, um conteúdo de cerceamento do poder decisório no interior do próprio grupo social, advindo de uma intervenção externa". Almeida (1996, p. 30), também define "deslocamento compulsório" como "o conjunto de realidades factuais em que pessoas, grupos domésticos, segmentos sociais e/ou etnias são obrigados a deixar suas moradias habituais, seus lugares históricos de ocupação imemorial ou datada, mediante constrangimentos, inclusive físicos, sem qualquer opção de se contrapor e reverter os efeitos de tal decisão, ditada por interesses circunstancialmente mais poderosos" (MAGALHÃES, 2007; ALMEIDA, 1996 apud ALVES, 2014)

${ }^{8}$ Reserva Extrativista é uma modalidade de unidade de conservação ambiental prevista no Sistema Nacional de Unidade de Unidade de Conservação (SNUC), conforme está instituído pela Lei nº. 9.985, de 18 de julho de 2000.

${ }^{9}$ ALVES, Elio de Jesus Pantoja. Repertórios e argumentos da mobilização política: um estudo sobre o Movimento Reage São Luís em São Luís-MA. XX f. 2014. Tese (Doutorado em Sociologia e Antropologia [Sociologia]) - Instituto de Filosofia e Ciências Sociais, Universidade Federal do Rio de Janeiro, Rio de Janeiro. 2014.

${ }^{10}$ MARTINS, Carolina C. de Souza; ALVES, Elio de Jesus Pantoja. O Terreiro do Egito no contexto das lutas políticas na Ilha do Maranhão. Boletim da CMF nº 61, dezembro 2016.

${ }^{11}$ Escritura Pública de Condomínio de 1998 - fotocópia de documento registrado no Cartório Alvimar Braúna, $4^{\circ}$ Ofício de Notas - R. Aracajú, 103, João Paulo - São Luís - MA.

${ }^{12}$ http://www.brasil.gov.br/infraestrutura/2016/01/governo-autoriza-novo-terminal-de-uso-privado-no-maranhao. Acesso em 12.01.2016

${ }^{13}$ Entrevista concedida aos membros do Grupo de Estudos: Desenvolvimento, Modernidade e Meio Ambiente da UFMA (GEDMMA) em 2014. O Grupo realiza pesquisas na região desde 2005.

${ }^{14}$ Conforme Asselim (2009), a "grilagem" de terras consiste na falsificação de documentos visando à obtenção de escrituras de terra em cartórios, garantindo a titulação da propriedade privada das mesmas. "Grileiros" são aqueles que detêm títulos de propriedade de terras por meio destes procedimentos.

${ }^{15}$ Carta Aberta Intitulada "Pelo Terreiro do Egito e Território do Cajueiro" elaborada por descendentes do Terreiro do Egito e por pesquisadores dos Grupos de Estudos da UFMA - GEDMMA e GPMINA em 22 de novembro de 2015.

${ }^{16}$ FERRETTI, Mundicarmo. O Terreiro do Egito e o navio encantado de Dom João. São Luís, 2015. (no prelo) ${ }^{17}$ ibid, 2015.

\section{Referências Bibliográficas}

ALMEIDA, Alfredo Wagner Berno de.Refugiados do desenvolvimento: os deslocamentos compulsórios de índios e camponeses e a ideologia da modernização. Travessia. Maio/agosto, 1996. pp. 30-35.

ALVES, Elio de Jesus Pantoja. Repertórios e argumentos da mobilização política: um estudo sobre o Movimento Reage São Luís em São Luís-MA. XX f. 2014. Tese (Doutorado em Sociologia e Antropologia [Sociologia]) - Instituto de Filosofia e Ciências Sociais, Universidade Federal do Rio de Janeiro, Rio de Janeiro. 2014.

Modos de vida, territórios e uma cidade em questão: resistências políticas de comunidades rurais no município de São Luís do Maranhão, Brasil. Revue Orda, v. 1, p. 1-50, 2016

ASSELIM, Vitor. Grilagem: corrupção e violência em terras do Carajás. Imperatriz: Ética, 2009. 
FERRETTI, Mundicarmo. A Encantaria de Barba Soeira: Codó, capital da magia negra? São Paulo: Siciliano, 2001

São Luís: UEMA. 2000. . Maranhão Encantado: encantaria maranhense e outras histórias.

.Lugares Sagrados e Encantarias Maranhenses. Anais da $56^{\mathrm{a}}$ Reunião Anual da SBPC - Cuiabá, MT - Julho/2004

. O Terreiro do Egito e o navio encantado de Dom João. São Luís, 2015. (no prelo)

FERRETTI, S. O Egito na memória da comunidade do Cajueiro. Boletim da Comissão Maranhense de Folclore, $\mathrm{n}^{\circ} 60$ junho de 2016. São Luís, 2016. Disponível em file://C:/Users/gedmm/Desktop/BOLETIM-DA-CMF-No-60-JUNHO-2016-ISSN-1516RECUPERADO-FINAL.

Laudo Sócio-Econômico e Biológico para Criação da Reserva Extrativista do Taim. Instituto Brasileiro do Meio Ambiente e dos Recursos Naturais Renováveis - IBAMA-MA. São Luís, 2006.

Laudo Sócio-Econômico e Biológico para Criação da Reserva Extrativista do Taim. Instituto Brasileiro do Meio Ambiente e dos Recursos Naturais Renováveis - IBAMA-MA. São Luís, 2007.

MARTINS, Carolina C. de Souza; ALVES, Elio de Jesus Pantoja. O Terreiro do Egito no contexto das lutas políticas na Ilha do Maranhão. Boletim da CMF nº 61, dezembro 2016.

MAGALHÃES, S. Barbosa. Lamento e Dor. Uma análise sócio-antropológica do deslocamento compulsório provocado pela construção de barragens. Tese de Doutorado. Programa de Pós-Graduação em Ciências Sociais - PPGCS/UFPA. Belém: UFPA, 2007.

MIRANDA, Ana C. Pires. Unidades de conservação da natureza x Indústrias potencialmente poluidoras: o caso da implantação da Reserva Extrativista de Tauá-Mirim. In: SANT'ANA JÚNIOR; H. A.; PEREIRA, M. J. F.; ALVES, E. J. P.; PEREIRA, C. R. A. (Orgs.). Ecos dos conflitos socioambientais: A RESEX de Tauá-Mirim. São Luís - M. São Luís, EDUFMA, 2009.

MOREIRA LIMA NETO, Bento. Histórias do Porto de Itaqui: crônica. Ideia Criativa: São Luís, 2007.

POLLACK, Michel. Memória, Esquecimento e Silêncio. Estudos Históricos. Rio de Janeiro, vol. 2, n. 3, 1999.

\section{Sites Visitados:}

http://www.brasil.gov.br/infraestrutura/2016/01/governo-autoriza-novo-terminal-de-usoprivado-no-maranhao. Acesso em 12.01.2016

http://repositorio.ufma.br:8080/jspui/bitstream/1/300/1/A\%2520TERRA\%2520DOS\%2520V ODUNS.pdf. Acesso em 03 jan. 2018.

http://www.planalto.gov.br/>. Acesso em: 30 jun. 2014. 